\title{
Willpower in children and adults: a survey of results and economic implications
}

\author{
Alessandro Bucciol • Daniel Houser • Marco Piovesan
}

Published online: 18 August 2010

(C) The Author(s) 2010. This article is published with open access at Springerlink.com

\begin{abstract}
This paper reviews key contributions to the psychology and economics literature on willpower. Understanding how willpower develops can shed important light on time-inconsistent economic decision making, a topic that has received substantial attention over recent decades. In particular, we argue that measures of willpower for the child provide useful insights into the nature of willpower and are reliable predictors of economic outcomes in the adult. The implication is that one might, for example, be able to strengthen a "weak" child's ability to resist temptation, and in so doing offer welfare enhancements not only to the child but also to the ultimate adult decision maker. Finally, we list a set of open questions that could be profitably addressed by the future research.
\end{abstract}

Keywords Willpower - Self-control problems · Child development

JEL Classification $\quad$ C93 $\cdot$ J13

The authors are grateful for the useful discussion to the participants of the 2009 Conference on "Economic Child" (Milan). The usual disclaimers apply.

A. Bucciol

Department of Economics, University of Verona, Verona, Italy

e-mail: alessandro.bucciol@univr.it

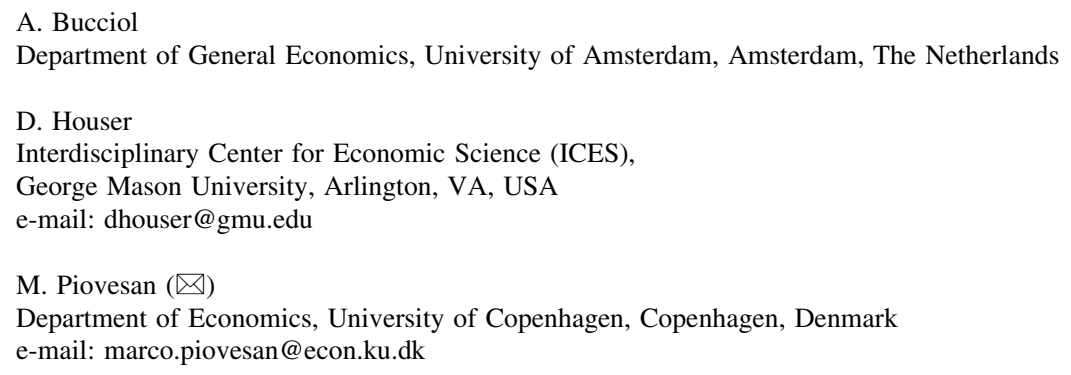




\section{Introduction}

Self-control problems commonly manifest as time-inconsistent preferences, that is, situations where planned future decisions and actual actions (when the future comes) do not perfectly coincide. For instance, a person can be determined not to order dessert and yet, when the decision has to be made, choose to order cake and ice cream. Self-control problems are often connected to a type of behavior with negative health outcomes (such as overeating or smoking) and have been linked also to procrastination (see, e.g., Loewenstein and Prelec 1992; Frederick et al. 2002; Thaler 1981). A recurring theme from these papers is that when evaluating (distant) future outcomes, individuals demonstrate patience and attentiveness to "healthful" lifestyles by making plans, for example, to go to the gym, to stop smoking and to work to obtain a better job. As the future draws nearer, however, individuals engage in binge eating and drinking behavior, choose to light another (last) cigarette and make little effort to change their job.

In parallel, a substantial literature in psychology ties self-control problems to willpower. In particular, psychologists have observed that self-control appears to be vulnerable to deterioration over time from repeated exertions, in the same way that a muscle becomes fatigued from repeated use. In this sense, willpower can be thought of as the energy used to control one's impulses, and willpower depletion can thus leave individuals more likely to succumb to temptations such as procrastination. Recently, this characterization of willpower has found support in a large number of experiments (see, e.g., Vohs and Heatherton 2000; Baumeister et al. 1994; Baumeister and Vohs 2003; Vohs and Faber 2007; Shiv and Fedorikhin 1999; Hinson et al. 2003).

For social scientists in general, this characterization of willpower suggests paths for new research on how to improve individuals' willpower and avoid willpower exertion. For economists in particular, investigating the willpower process might shed important new light on time-inconsistent economic decision making.

In this regard, it is crucial to understand how willpower develops from childhood to adulthood. Indeed, measures of willpower for the child may provide useful insights into the nature of willpower, and these may also be reliable predictors of economic outcomes in the adult. In this respect, Mischel and Metzner (1962) and Mischel and Mischel (1983) found evidence that the ability to delay gratification and resist temptation is positively related to age: as children grow older they become more skilled in self-control, and also increasingly discover how to employ self-control strategies to overcome temptations.

The idea that willpower is a limited resource that can be trained but also exhausted has important economic consequences. The knowledge that self-control activity requires energy, and that this energy depletion can affect individuals' behavior in other domains, might affect policy and institution design in all those fields where self-control problems are present. Moreover, ignoring this evidence may produce ineffective policies. For instance, ego depletion is assumed to underpin overeating by dieters (Vohs and Heatherton 2000), prejudicial responding (Richeson and Shelton 2003), underachievement in intellectual pursuits (Schmeichel et al. 2003), inappropriate sexual responses (Gailliot and Baumeister 2007), and 
impulsive overspending (Vohs and Faber 2007). Being unable to provide willpower effort in these activities may preclude one from achieving a desirable goal.

The remainder of this paper is organized as follows. We first review the existing literature on willpower, self-control problems and temptation and we cite initial attempts to model and test these behaviors in economics (Sect. 2). We then argue that it is important to understand the nature of willpower and its development in order to anticipate and prevent self-control problems that can lead to timeinconsistent decision making. Specifically, we concentrate our attention on the relationship between willpower and child development (Sect. 3), and willpower, child development and productivity (Sect. 4). Finally, we draw attention to a set of open questions that could be profitably addressed by future research (Sect. 5).

\section{Willpower in adults}

The topic of willpower has been investigated in different disciplines. In economics, "bounded willpower" is the tendency to make decisions which are in conflict with the long-run interest; for instance, bounded willpower may lead to addictive behavior, under-saving, or procrastination.

Popular models of bounded willpower are the dual-self model (Thaler and Shefrin 1981), the quasi-hyperbolic discounting model (Laibson 1997) and the temptation model (Gul and Pesendorfer 2001). In the dual-self model, human decisions are the results of two conflicting traits of personality: a "doer" trait caring only about current well-being, and a "planner" trait caring about the well-being of all the doers. The tension between the two traits determines the actual decision. In the quasi-hyperbolic discounting model, the decision maker is seen as a sequence of independent "selves" that make their choice in a dynamic, intrapersonal game. Taking the strategies of future selves as given, each self chooses a behavior that is optimal from her perspective. Future utilities are discounted at a rate generating a bias toward the present. Time inconsistency arises because the strategies of future selves actually differ when the future comes. In the temptation model, utility depends on the actual decision as well as the set of options from which the choice is made. An agent first identifies the most tempting alternative taking a short-run perspective, and then she makes the actual choice taking a long-run perspective. However, the tempting alternative biases the behavior toward decisions rewarding more in the short run.

In all these models, agents have both a short-run preference for instantaneous gratification and a long-run preference for lifetime goals, which connects with findings on the modular structure of the brain where the limbic system and the prefrontal cortex are seen, respectively, as locations for emotions and rational planning (McClure et al. 2004). Commitment plays an important role in these models to correct the behavior toward long-run goals. The subject has received some attention in experimental economics (see, e.g., Houser et al. 2008b). For example, Malmandier and Della Vigna (2006), using data from three US health clubs offering a choice between monthly contract (with unlimited attendance) and a pay-per-visit contract, found that users choosing a monthly contract attend the gym 
a number of times insufficient to justify this contract choice. For the user, in fact, it would be more convenient to choose the pay-per-visit contract. This finding suggests that users overestimate their future health club attendance. Another interpretation is that they use the monthly contract as an (expensive) commitment device. This contract, in fact, reduces the marginal cost of a visit to zero and may help to align actual and desired attendance.

What the most popular models of bounded willpower disregard is the psychological concept of "ego depletion". Individuals have only a limited supply of energy, and exerting self-control in activities requiring willpower reduces this supply. In particular, activities requiring self-control compromise the capacity of individuals to preclude an undesirable behavior, such as eating excessively. The experimental literature seems to support this theory. For instance, Baumeister and his colleagues have shown that individuals who have executed tasks requiring selfcontrol are later less able to perform other tasks also requiring self-control (e.g., Muraven et al. 1998). A particularly interesting study in this regard is Vohs and Heatherton (2000), which reports data from an investigation designed to test the hypothesis that people on a diet expend willpower to avoid consuming snacks, and that this willpower expenditure can affect subsequent willpower-related decisions in other domains. In their study, adults on a diet sat for a period of time in a waiting room either with tempting snacks nearby (the "temptation" treatment) or far away (the control treatment). Then, participants were directed to a new location and asked to solve a series of difficult puzzles. Compared to the control condition, they found that subjects exposed to temptation were less persistent in their effort to obtain solutions.

In a similar vein, Houser et al. (2008a) take advantage of a natural experiment to demonstrate that "tempting" goods are more likely to be purchased from the checkout aisle when the wait-time is longer, because the prolonged tension between short-run and long-run goals reduces the supply of willpower. Ozdenoren et al. (2005) show that the "depletion hypothesis" can provide an explanation for the empirical evidence on commitment, intertemporal preference reversals and procrastination. They propose a model in which an agent has to decide how to optimally consume a cake over time. This agent also knows that restraining his consumption too much would exhaust his willpower and leave him unable to manage his consumption in the future. Therefore, depletion provides an explanation for a taste for commitment and it may explain phenomena as intertemporal preference reversals and procrastination. In this paper, they also conjecture that exercising self-control depletes willpower over the short run but it strengthens it over the long run, like a muscle that gets tired but builds up strength. The existing evidence strongly suggests that further work has to be done in order to understand how to develop and strengthen willpower. In particular, the connection between willpower depletion and economic decisions has not been explored sufficiently.

Marketing seems to have understood that the "willpower muscle" can become fatigued. In fact, clever sales employees often make a predefined sequence of requests to their potential customers (e.g., Fennis et al. 2009). The first request is intended to demand careful deliberation, consuming resources from a limited supply of effort or energy. When these resources are depleted, customers do not consider 
subsequent decisions carefully, and end up more willing to do as the sales employees prefer.

Ego depletion might also curb some of the traditional self enhancement biases (see Fischer et al. 2007). That is, individuals frequently overestimate their skill and attributes ("above average skill"), they feel they can control random forces ("sense of control"), and they believe they are not vulnerable to undesirable events, such as skin cancer or vehicle crashes ("optimism bias"). In order to sustain these biases, individuals deliberately shift their attention away from their limitations and concentrate only on their strengths and opportunities. However, this shift requires self-control. Therefore, individuals may be less likely to demonstrate these biases after undertaking other tasks requiring self-control, which are costly in terms of willpower. Fischer et al. (2007) present evidence in line with this intuition. In their experiment, they found that people with depleted self-regulatory resources exhibited: (i) a less-optimistic sense of their own abilities; (ii) a lower sense of subjective control; (iii) less-optimistic expectations about their future.

All this evidence suggests that when that energy (willpower) is low, mental activity that requires self-control is impaired. In other words, using one's selfcontrol impairs the ability to control one's self later on. Of course, not all individuals enjoy the same level of willpower. More interestingly, willpower is not exclusively determined by "nature", but it is also something that can be trained as we grow older (Mischel and Metzner 1962). Hence, profitable effort could made to better understand the process by which we develop self-control, as well as the expected costs and benefits associated with its use. With this information available, it could perhaps be eventually possible to develop institutions that promote willpower's effectiveness.

\section{Willpower and child development}

Mischel and Metzner (1962) found evidence that the ability to delay gratification, or resist temptation, is positively related to age. The reason is that as children become older they increasingly discover how to employ these self-control strategies (Mischel and Mischel 1983). When children are very young they often use strategies that make delay difficult, including "to expose the rewards during the delay period and to think about them, (for example, "because it makes me feel good"), thus defeating their own efforts to wait" (Mischel et al. 1989, p. 936). Growing older, their strategies slowly become more experienced and by around their fourth of fifth grade many children are able to delay gratification by focusing on abstract rather than arousing thoughts.

Since then, research has typically concentrated on the development of willpower in childhood. The ultimate test of how much willpower a children has involves resisting the temptation of eating a marshmallow. In a well-known experiment in the late 1960s, Mischel and Ebbeson (1970) showed 4-year-old children a marshmallow and they told them they could have eaten one right away, or they could have had a second one if they were willing (and able) to wait for $15 \mathrm{~min}$. If children had chosen to wait and have the second marshmallow, they had to remain alone in a room 
seated in front of their temptation. In experiments with this setup, many children initially declare they want to wait for the second marshmallow, but then, when left alone, they change their mind and opt for eating the first marshmallow immediately. In the original experiment some chose the single marshmallow very soon, while $30 \%$ were able to wait until the researcher returned. The remaining children claimed they could wait but after few minutes they gave up.

Even if resisting a single marshmallow (or a cigarette, an impulsive purchase, a visit to the gym) may seem a trivial exercise, exerting self-control in this framework can predict fairly well success and failure over the course of life in many different areas. Mischel (1996) followed up 20 years later the same group of children taking part in their first experiment. Surprisingly they found that those who had previously waited for $15 \mathrm{~min}$ had an average SAT score that was 210 points higher than those who had waited for just thirty seconds or less. Moreover, these people had more rewarding social relationship and fewer behavioral problems.

In order to check whether or not self-control strategies could be learned, Mischel repeated the experiment with the same children, but under small deviations from the original design. Children were taught some mental tricks and mental transformation-for instance pretending that the marshmallow is not real but only a picture or a cloud. Freud (1959) already thought that young children develop the capacity of deferring gratification by forming mental images of desired stimuli. His idea was that they can resist a temptation by enjoying a mental picture of this temptation in place of the real objects. However, the experiment of Mischel found that Freud was only partly right: keeping a temptation in mind, and thereby maintaining an expectation of it, leads children quickly into temptation, whereas encouraging them to form abstract, non-arousing (or "cold") cognitive representations facilitates waiting. In the experiment, children who previously had been able to wait only few seconds could now wait for the entire period once forming cold representations. Mischel concluded that "Once you realize that willpower is just a matter of learning how to control your attention and thoughts, you can really begin to increase it." This finding has enormous implications. If willpower and self-control can be really improved and strengthened, then it is also possible to improve children's future success in life.

In view of this research, it makes sense to investigate how children's willpower works in a more "adult" environment, as one involving productivity. Testing how willpower works in children may have an educational purpose. Indeed, detecting the common characteristics of children with little willpower can help taking actions aimed to strengthen this "muscle" and increase the probability of making a better career.

\section{Economic implications}

Every day, people resist the impulse to eat junk food, to say inappropriate things, to cheat on their partner and so on. Self-control also forces individuals to follow rules and norms prescribed by the society rather than undertaking a more selfish behavior. 
Behaving in an appropriate way requires energy that must then be subtracted from other domains. The same is true in the workplace: sometimes it is difficult to concentrate on the boring task at hand, and thus we can find ourselves tempted to play instead of working. For instance, many businesses rely on the Internet, and this means Internet temptations are a largely unavoidable part of today's workplace. In particular, social networking on Facebook or MySpace, shopping on Amazon or eBay, or spending time with personal email are only a mouse-click away for office employees. Consequently, in order to encourage workers' productivity, many offices adopt policies monitoring the Internet use during work hours. As a result, rather than succumbing to the Internet temptation, many employees will delay their gratification by waiting to use the Internet until their workday ends. However, evidence provided above argues that self-control is a deliberative, conscious and effortful action, and moreover that using willpower to delay gratification can impact performance on subsequent tasks. Therefore, prohibiting or controlling employees' temptation can decrease their productivity, slow down reaction times and increase errors and lapses in vigilance.

Bucciol et al. (2009) demonstrate a clear relation between willpower depletion and productivity. Using standard economic theory, they develop a model showing that, when delaying gratification is difficult, exposure to a tempting good detrimentally impacts productivity; in contrast, when delaying gratification is easy, it can lead to productivity gains. In their model, individual earnings and productivity are directly linked to costly effort; rational agents determine their optimal effort by maximizing an objective function given by earnings net of the effort cost. Earnings and productivity are high when the effort cost is small. However, the external environment may force agents to exert willpower and increase their effort in order to get the same productivity. Depending on the nature of the cost function, productivity may fall when exerting effort is very costly (i.e., when it is inefficiently managed), or even rise when exerting additional effort comes at no cost). In particular, this implies that when delaying gratification is difficult, exposure to a tempting good detrimentally impacts productivity while, when delaying gratification is easy, exposure to temptation can lead to productivity gains.

Bucciol et al. (2009) proceed to report findings from a field experiment with children aged from 6 to 13 because, as mentioned above (see Mischel and Metzner 1962), willpower systematically increases with experience as children grow older. By exploiting this exogenous variation, the authors seek to obtain clean evidence on the link between willpower, temptation and productivity. Their data suggest that exposure to a prohibited tempting item significantly affects productivity on a subsequent task, but this effect differs with age. In particular, the impact is negative with children younger than 8 years old and positive with children older than 10 years old. An interpretation is that temptation just creates costly selfcontrol problems in the youngest children, while older children are successfully able to use the repetitive production task as a distracting device to facilitate selfcontrol: working vigorously on the task is a strategy used to focus one's attention away from the tempting items, similarly to the "cold" representation in Mischel's experiments. 


\section{Discussion and future research}

As indicated by the research reported by the contributors to this volume, economists now recognize the importance of understanding children's behavior. Understanding the preferences and decisions of children is important in its own right and also provides potential insights into adult behavior. In the case of willpower, we pointed out that it varies systematically with age. The implication is that measures of willpower for the child might reliably predict economic outcomes in the adult. If so, then one might, for example, strengthen a "weak" child's ability to resist temptation, and in so doing offer welfare enhancements not only to the child but also to the ultimate adult decision maker.

Studies of willpower are still in their early stages, and much remains to be discovered. Future theoretical advances will more clearly tie down the rate at which willpower is depleted, whether this rate might systematically vary with observable characteristics of the decision maker (e.g., gender or age) or the environment within which the decisions take place. Empirical research, in addition to validating the hypotheses stemming from such economic theory, will also explore the neural foundations of temptation and self-control. First steps in this area have been taken (see, e.g., Hare et al. 2009), and future work on the biological (including of course genetic) bases of willpower promises to have not only clinical applications (say to the treatment of compulsive gambling), but also broad relevance to fields including economics, psychology, public policy, philosophy and law.

Open Access This article is distributed under the terms of the Creative Commons Attribution Noncommercial License which permits any noncommercial use, distribution, and reproduction in any medium, provided the original author(s) and source are credited.

\section{References}

Baumeister RF, Vohs KD (2003) Willpower, choice and self-control. In: Lowenstein G, Read D, Baumeister R (eds) Time and decision: economic and psychological perspectives. Russell Sage Foundation, New York, NY

Baumeister RF, Heatherton TF, Tice DM (1994) Losing control: how and why people fail at selfregulation. Academic Press, San Diego, CA

Bucciol A, Houser D, Piovesan M (2009) Temptation at work: a field experiment on willpower and productivity. ICES Working paper no. 1013, George Mason University

Fennis BM, Janssen L, Vohs KD (2009) Acts of benevolence: a limited-resource account of compliance with charitable requests. J Consum Res 35:906-924

Fischer P, Greitemeyer T, Frey D (2007) Ego depletion and positive illusions: does the construction of positivity require regulatory resources? Pers Soc Psychol Bull 33:1306-1321

Frederick S, Loewenstein G, O'Donoghue T (2002) Time discounting and time preference: a critical review. J Econ Lit 40:351-401

Freud S (1959). Collected papers. New York Basic Books 4: 13-21

Gailliot MT, Baumeister RF (2007) Self-regulation and sexual restraint: dispositionally and temporarily poor self-regulatory abilities contribute to failures at restraining sexual behaviour. Pers Soc Psychol Bull 33:173-186

Gul F, Pesendorfer W (2001) Temptation and self-control. Econometrica 69:1403-1435

Hare TA, Camerer CF, Rangel A (2009) Self-control in decision-making involves modulation of the vmPFC valuation system. Science 324:646-648 
Hinson J, Jameson T, Whitney P (2003) Impulsive decision making and working memory. J Exp Psychol Learn Mem Cogn 29:298-306

Houser D, Reiley D, Urbancic M (2008a) Checking out temptation: a natural experiment at the grocery checkout aisle. Working paper, George Mason University

Houser D, Schunk D, Winter J, Xiao E (2008b) A laboratory analysis of willpower and self-control. Working paper, George Mason University

Laibson D (1997) Golden eggs and hyperbolic discounting. Q J Econ 112:443-477

Loewenstein G, Prelec D (1992) Anomalies in intertemporal choice: evidence and an interpretation. Q J Econ 107:573-597

Malmandier U, Della Vigna S (2006) Paying not to go to the gym. Am Econ Rev 96:694-719

McClure SM, Laibson DI, Loewenstein GF, Cohen JD (2004) Separate neural systems value immediate and delayed monetary rewards. Science 306:503-507

Mischel W (1996) From good intentions to willpower. In: Gollwitzer PM, Bargh JA (eds) The psychology of action: linking cognition and motivation to behavior. Guilford, New York

Mischel W, Ebbeson EB (1970) Attention in delay of gratification. J Pers Soc Psychol 16:329-337

Mischel W, Metzner R (1962) Preference for delayed reward as a function of age, intelligence, and length of delay interval. J Abnorm Soc Psychol 64:425-431

Mischel HN, Mischel W (1983) The development of children's knowledge of self-control strategies. Child Dev 54:603-619

Mischel W, Shoda Y, Rodriguez ML (1989) Delay of gratification in children. Science 244:933-938

Muraven M, Tice DM, Baumeister RF (1998) Self-control as limited resource: regulatory depletion patterns. J Exp Soc Psychol 74:774-789

Ozdenoren E, Salant S, Silverman D (2005) Willpower and the optimal control of visceral urges. NBER working paper no. 12278

Richeson JA, Shelton JN (2003) When prejudice does not pay: effects of interracial contact on executive function. Psychol Sci 14:287-290

Schmeichel BJ, Vohs KD, Baumeister RF (2003) Ego depletion and intelligent performance: role of the self in logical reasoning and other information processing. J Pers Soc Psychol 85:33-46

Shiv B, Fedorikhin A (1999) Heart and mind in conflict: the interplay of affect and cognition in consumer decision making. J Consum Res 26:278-292

Thaler R (1981) Some empirical evidence on dynamic inconsistency. Econ Lett 8:201-207

Thaler RH, Shefrin HM (1981) An economic theory of self-control. J Polit Econ 89:392-406

Vohs KD, Faber RJ (2007) Spent resources: self-regulatory resource availability affects impulse buying. J Consum Res 33:537-547

Vohs KD, Heatherton TF (2000) Self-regulatory failure: a resource-depletion approach. Psychol Sci 11:249-254 